\title{
ОСОБЕННОСТИ ПРАВОВОГО РЕГУЛИРОВАНИЯ КРИПТОВАЛЮТЫ В РОССИИ И ЗАРУБЕЖНЫХ СТРАНАХ
}

\author{
(c) 2021 Лошкарев Андрей Викторович \\ кандидат юридических наук, доцент \\ Самарский государственный экономический университет \\ E-mail:2482337@mail.ru

\section{(c) 2021 Кутовой Ян Сергеевич} \\ студент \\ Самарский государственный экономический университет \\ E-mail: yan_kutovoy@bk.ru
}

\begin{abstract}
Сравнительный анализ правового регулирования криптовалюты в разных странах позволит сделать совокупный вывод об имеющихся возможностях применения криптовалюты. В статье выявлены основные проблемы правового регулирования криптовалюты, а также тенденции и пути развития, выработаны рекомендации для минимизации рисков при обращении с криптовалютой.
\end{abstract}

Ключевые слова: криптовалюта, правовое регулирование, цифровая валюта, цифровые финансовые активы.

В российском государстве уже предпринята попытка принять нормативные акты, которые бы определили правовой статус криптовалюты. Однако, Российская Федерация находится еще только на пути к становлению законодательной базы, регулирующей отношения связанные с криптовалютой.

Остается очень много пробелов в нормативно-правовом регулировании, в связи с чем складывается судебная практика, при которой суд далеко не всегда встает на сторону потерпевшей стороны.

В настоящее время единой позиции у отечественных и зарубежных ученых относительно определения понятия криптовалюты до сих пор не сложилось. Криптовалюта, как правило, рассматривается в качестве объекта гражданских прав, в качестве цифровой валюты, цифрового имущества, товара, средства платежа, а иногда даже как обязательственное право. Валютой, существующей только в электронном виде называют цифровую валюту [1].

Цифровая валюта классифицируются по способу регулирования и подразделяются на следующие: виртуальная валюта и регулируемая центральным банком.

Виртуальной валютой являются цифровые деньги, которые не регулируются центральным банком, контролировать которые может только сам разработчик. К виртуальной валюте также относятся электронные деньги.
Криптовалюту возможно классифицировать исходя из следующего: по популярности (популярные, не популярные); по курсу и капитализации (котируемые на бирже и не котируемые); по сфере применения (полноценные аналоги электронных денег, аналоги, созданные для банков, безопасные (надежные), приватные, удобные); по происхождению (созданные одним лицом, группой лиц, организацией); по перспективе развития (перспективные и неперспективные); по отношению к криптовалютам (признанные странами, непризнанные странами, введенные странами).

Поскольку криптовалюта в настоящее время является не только средством осуществления платежей, но и объектом инвестирования сперва рассмотрим вопрос правового регулирования выпуска и размещения криптовалюты.

Вопрос правового регулирования выпуска и размещения криптовалюты является актуальным, поскольку криптовалюта в настоящее время является не только средством осуществления платежей, но и объектом инвестирования.

Первой попыткой регулирования криптовалюты в России является сообщение Банка России от 27 января 2014 г., в котором говорится о том, что «криптовалюта не обеспечена ни одним государством и нет юридически ответственных субъектов по ним. Транзакции с криптовалютой имеют спекулятивный характер, осуществляется на незаконных цифровых биржах и имеет высо- 
кий риск потери ценности. Также высок финансовый риск, поскольку цифровые транзакции не защищены законом».

В 2017 г. Центральный Банк РФ подтвердил свою позицию 2014 г., опубликовав информационное сообщение «Об использовании частных «виртуальных валют (криптовалют)», согласно которому, не допускает к обращению и не обслуживает сделки с криптовалютой [2].

Нормативно-правовое регулирование в области отношений, связанных с регулированием криптовалюты в России стало активно развиваться с 2017 г.

Так, в целях развития информационного общества и формирования национальной цифровой экономики в Российской Федерации Указом Президента РФ от 9 мая 2017 г. № 203 была утверждена «Стратегия развития информационного общества в Российской Федерации на 2017-2030 годы».

Министерством финансов РФ был подготовлен законопроект «О цифровых финансовых активах». Создание законопроекта обусловлено необходимостью подготовки нормативноправовой базы для регулирования отношений, которые возникли в области информационных технологий [3].

Первоначально законопроект содержал положения о криптовалюте, которые впоследствии убрали из него.

В январе 2018 года технология блокчейн была внедрена в документооборот Федеральной таможенной службы, с целью использовать её для верификации сертификатов происхождения товаров, что повысило контроль качества ввозимых в страну товаров.

18 марта 2019 г. приняли Федеральный закон № 34-Ф3 «О внесении изменений в части первую, вторую и статью 1124 части третьей Гражданского кодекса Российской Федерации», который дополнил Гражданский кодекс РФ статьей 141.1 «цифровые права», данное понятие было введено впервые [4].

В соответствии с п. 1 ст. 141.1 ГК РФ цифровыми правами признаются «названные в таком качестве в законе обязательственные и иные права, содержание и условия осуществления которых определяются в соответствии с правилами информационной системы, отвечающей установленным законом признакам.

Осуществление, распоряжение, в том числе передача, залог, обременение цифрового пра- ва другими способами или ограничение распоряжения цифровым правом возможны только в информационной системе без обращения к третьему лицу.

Относительно данного «нововведения», авторы Белых В.С., Болобанова М. О. в своей работе пишут, что «экономическая природа понятия «цифровой финансовый актив» противоречит его правовому определению и предполагаемому в проектах законов правовому режиму» [5].

Исходя из положений данной статьи можно сделать вывод, что, под цифровыми правами понимается право на криптовалюты. Однако в принятом законе не содержится определение объекта права.

В соответствии с п. 1 ст. 141.2 ГК РФ в редакции законопроекта № 424632-7, представленного к первому чтению, «цифровыми деньгами может признаваться не удостоверяющая право на какой-либо объект гражданских прав совокупность электронных данных (цифровой код или обозначение), созданная в информационной системе, отвечающей установленным законом признакам децентрализованной информационной системы, и используемая пользователями этой системы для осуществления платежей» [6].

Данное определение, к большому сожалению, исключили из текста законопроекта на основании Официального отзыва Правительства РФ на проект Федерального закона № 424632-7, принятый Государственной Думой в первом чтении 22 мая 2018 г., в связи с тем, что данная норма не соответствует ст. 75 Конституции РФ [7].

С января 2021 года вступил в законную силу федеральный закон «О цифровых финансовых активах, цифровой валюте и о внесении изменений в отдельные законодательные акты Российской Федерации» [8].

Изначально законопроект содержал термин «криптовалюта», однако в итоге он был заменен на термин «цифровая валюта». Основные детали данного термина заключаются в том, что цифровой валютой признается совокупность электронных данных в системе, ей возможно оплачивать, или сохранить как инвестиции, несмотря на то, что она не является денежной единицей.

Термин «цифровая валюта», введённый настоящим федеральным законом, не приравнивается к термину «криптовалюта», поскольку механизм получения и экономическая ценность криптовалюты говорит о том, что она обладает имущественной стоимостью, может быть пред- 
метом сделки, на нее может быть обращено взыскание.

Из-за значительных пробелов в законе ситуация для сторон криптобизнеса осталась без изменений. В мировом сообществе во многих странах терминология в законах о криптовалюте уже была изобретена, однако в России ей не воспользовались, придумав свои собственные термины, которые создают неопределенность и путаницу.

По факту новый закон стал основой для цифровизации отечественных активов, которые крайне сложно выводить на международный рынок.

За пределами Закона О ЦФА осталось понятие майнинг, как вид деятельности. Также имеются противоречия, в частности, в законе цифровую валюту признают, как средство платежа и инвестицию, однако в ст.14 регламентировано, что в России ни физические, ни юридические лица не имеют право принимать цифровую валюту в качестве оплаты за предоставленные услуги, или товары, или в качестве оплаты иным образом.

Более того, для получения судебной защиты собственнику валюты необходимо оплачивать налоги, получается, что неуплата налогов влияет на право собственности, что также представляется не совсем корректным.

Банком России в апреле 2021 г. была представлена концепция цифрового рубля. Так, согласно вышеназванной концепции, данная платформа должна будет выпущена в декабре 2021 года, на 2022 год запланированы соответствующие тестирования. Только после тестирования правительством будет принято решение, о том, каким именно образом будет реализована и внедрена данная платформа.

Банк России обещает установить единые для всех правила и тарифы, предварительно сообщая, о том, что все переводы между физическими лицами будут производиться бесплатно.

Предположительно, цифровые рубли могут быть использованы как для накоплений, так и для платежей. В будущем, возможно, они полностью заменят бумажные деньги. Таким образом, государство сможет отслеживать все операции. Открыть такой счет будет возможно только в ЦБ. Цифровые рубли будут находиться непосредственно в электронных кошельках ЦБ.

Банк России будет выступать эмитентом цифрового рубля, также будет разработано специальное мобильное приложение для хранения денежных средств. В приложении будет функционировать 2-й кошелек, отвечающий за офлайн операции, в том числе при расчетах в обычных магазинах. Пополнить второй кошелек будет возможно через первый.

Анализ нормативно-правовой базы Российской Федерации в области регулирования криптовалют помог выделить следующие проблемные моменты при её майнинге и обращении:

Обращение криптовалюты никем не контролируется, что несет в себе высокие риски при проведении обменных операций и привлечения инвесторов, в связи сильным колебанием курса.

Отсутствие договорных отношений с оператором, держателем криптовалюты, в связи с чем, все операции являются необратимыми, их невозможно отменить, что может привести к финансовым потерям и невозможности защиты своих прав.

У криптовалюты отсутствует обеспечение (валютой, драгоценными металлами), однако ее возможно обменять на государственную валюту фактически любого государства.

Правовой статус криптовалюты не определен. Отсутствие единого мнения у разных ведомств относительно криптовалюты, поскольку нет законодательного регулирования. Проблема определения правового статуса криптовалюты, имеет место быть, поскольку в действующем российском законодательстве использование криптовалют не урегулировано.

Все вышеуказанные проблемные моменты обуславливают активное использование криптовалют в преступной деятельности (торговля оружием, наркотиками, поддельными документами, финансирование терроризма).

В связи с отсутствием у криптовалюты контролирующего органа сделки с ней не подлежат обжалованию, невозможно отменить транзакцию, участники таких отношений становятся уязвимы в плане отстаивания своих интересов в суде.

Таким образом, можно сделать вывод, что Российская Федерация находится еще только на пути к становлению законодательной базы, регулирующей отношения связанные с цифровизацией экономики и криптовалютой. Правовой статус криптовалюты не определен. Отсутствие единого мнения у разных ведомств относительно криптовалюты, поскольку нет законодатель- 
ного регулирования. Проблема определения правового статуса криптовалюты, имеет место быть, поскольку в действующем российском законодательстве использование криптовалют не урегулировано.

Проанализировав зарубежную практику нормативно-правового регулирования криптовалюты следует отметить следующее. За рубежом отношения с криптовалютой у государств складываются по-разному, одни страны её принимают, создавая нормативно-правовую базу для её регулирования, другие до сих опасаются.

Самая первая страна, принявшая криптовалюту стала Япония. С 2017 года она была признана, как средство платежа. Криптовалюта там приравнивается к электронным деньгам, таким образом, она конечно не является денежным средством, но ей возможно производить оплату. В Японии была создана Комиссия по цифровым активам, считающаяся саморегулируемым органом, также там действует закон «О платежных услугах».

В Республике Беларусь Декретом № 8 Президента Республики Беларусь «О развитии цифровой экономики» от 21.12.2017 г. в целях развития и построения цифровой экономики создаются условия для внедрения в экономику технологии реестра блоков транзакций (блокчейн), а также иных технологий основанных на принципах распределенности, децентрализации и безопасности совершаемых с их использованием операций [9].

До принятия настоящего Декрета обращение криптовалюты в Беларуси не было урегулировано на законодательном уровне. С принятием настоящего Декрета в Республике Беларусь юридическим лицам разрешено владеть токенами (хранить их в виртуальных кошельках), создавать, размещать их на территории Республики и за рубежом, также, приобретать, отчуждать, и совершать с ними иные сделки.

Физическим лицам разрешено владеть, заниматься майнингом, осуществлять хранение, обмениваться токенами, дарить, завещать, приобретать и отчуждать. Операторы криптовалюты имеют право открывать счета в банках, кредитно-финансовых и небанковских организациях Республики и за рубежом. Более того, до 1 января 2023 г. криптовалюта в Республике не подлежит налогообложению.

В Германии в 2018 г. Министерством финансов было дано разъяснение по поводу бит- койнов. Так, уже в 2018 г. было определено, что биткойн является не электронными деньгами или функциональной валютой, а «единицей расчета», «финансовым инструментом», «частными деньгами» [10]. Федеральное ведомство по контролю за финансовыми услугами отнесло биткойн к валюте. Также в этой стране есть компания, позиционирующая себя в качестве криптобанка - Bitwala, в котором обеспечена защита вкладов на сумму до 100000 евро.

В Италии криптовалюта, а также блокчейнтехнологии регулируется за законодательном уровне.

В 2017 году Законодательным актом № 90, криптовалюта была приравнена к обычным деньгам, при этом постановлением от 02.02.2018 г. правительством Италии было закреплено, что криптовалюта является интрументом для отмывания денежных средств, которые получены преступным путем, финансирования терроризма, а также, что криптовалюта не является средством платежа.

Швейцария в руководстве FINMA (Управление надзора за операциями финансового рынка) к ценным бумагам приравнивает только инвестиционные токены, а биткойн и эфириум данной страной не рассматриваются как ценные бумаги.

FINMA выделяет 3 вида токенов:

- платежные (криптовалюта), например биткоин, эфириум;

- утилитарные, дающие доступ для использования услуг, которые предоставляются при помощи блокчейна.

- инвестиционные. Например, акции и облигации.

Также отмечается, что токены могут попасть сразу в несколько категорий, представляя из себя ценную бумагу и одновременно платежное средство.

При этом 26 августа 2019 г. швейцарский регулятор FINMA впервые выдал двум блокчейнкомпаниям (SEBA Crypto и Sygnum) банковские лицензии.

В США рынок криптовалюты сегодня отчасти регулируется. Использование криптовалюты достаточно жестко контролируется. В 2018 г. криптовалюта была приравнена к товару, в первую очередь для того, чтобы криптовалютные операции облагались налогом.

Все компании, занимающиеся криптовалютными операциями в обязательном порядке 
должны быть зарегистрированы в специальном реестре, который имеет государственный статус. Операции, производимые с криптовалютой подлежат обязательному налогообложению. Токены в США приравниваются к ценным бумагам.

Австралия рассматривает криптовалюту как товар, деятельность, связанная с криптовалютой не подлежит лицензированию, поскольку криптовалюта не рассматривается в качестве финансового продукта. Налоговая там взяла на себя официально мониторинг биткойна.

К криптовалютным транзакциям применяется система налогообложения как к товарным операциям. Операции с криптовалютой облагаются подоходным налогом и налогом на прибыль.

Там действует Кодекс поведения для игроков индустрии цифровых валют, которым устанавливаются надлежащие стандарты ведения криптовалютного бизнеса в стране. При инвестировании криптовалюты налог на прирост капитала отсутствует. Интересно, что в Австралии возможно получать зарплату криптовалютой, если будет достигнуто соглашение между сотрудником и работодателем.

Китай расценивает криптовалюту как виртуальный товар. В 2013 году было разрешено всем желающим вести деятельность с криптовалютой. В 2014 году всем организациям было рекомендовано закрыть счета интернет -ресурсов, которые осуществляли работу с биткойном.

Налогообложению подлежат операции при обмене, покупке, продаже криптовалюты как физическими, так и юридическими лицами.

Народный банк Китая пытается создать национальную валюту, которую начали тестировать в феврале 2017 г. Технология блокчейн там поддерживается.

Сейчас в 2021 году в Китае вводятся жесткие санкции в отношении транзакций криптовалюты, всем финансовым организациям запрещено предоставлять услуги по регистрации, торговле, клирингу и производить расчеты с криптовалютой.

В Сингапуре налоговая служба государства в 2014 г. признала биткойн как товар или услугу. Также к криптовалюте применяется законодательство по противодействию терроризма и отмыванию денег.

Операции с криптовалютой в Сингапуре облагаются корпоративным подоходным налогом (17\%). Криптовалютные биржи подлежат реги- страции и находятся под контролем MAS.

Биткоин, как показал наш обзор выше, вполне может претендовать на статус глобальной валюты, несмотря на его очевидные недостатки. Главным преимуществом биткоина является его реальная децентрализация.

Тот факт, что создатель биткоина не известен (Сатоши Накамото лишь псевдоним) и не пытается управлять процессами, внушает оптимизм тем, кого криптовалюта привлекает именно неподконтрольностью некой центральной власти, неважно - государственной или частной.

Будет сильным упрощением и вульгаризацией воспринимать этих сторонников криптовалют исключительно как представителей криминального мира.

Большинство из них разделяют идеи криптоанархизма, выступая за использование асимметричной криптографии для обеспечения соблюдения принципов конфиденциальности и индивидуальной свободы. Именно такие «идейные» криптоинвесторы поддерживают новые глобальные проекты по разработке криптовалюты принципиального нового уровня.»

Представляется, что именно это вызывает настороженное отношение к криптовалютам со стороны государств. Многие опасения, которые высказывались на первых этапах распространения криптовалют, уже очевидно не сбылись.

Криптовалюты не признаются и угрозой для мировой финансовой стабильности, о чем заявили лидеры стран «Большой двадцатки» на саммите в Буэнос-Айресе в марте 2018 г.

Тем не менее последние крупные проекты по созданию криптовалют, рассчитанные на многомиллионную аудиторию социальных сетей (Facebook, Telegram), были запрещены властями США. Жесткую позицию по поводу криптовалют занимает и Россия [11].

Проведя анализ правового регулирования криптовалюты в России и зарубежных странах следует отметить, что после закрепления на законодательном уровне понятийного аппарата, связанного с криптовалютой, законодателю будет необходимо определить основные «моменты» относительно внесения поправок российское законодательство.

В совокупности из представленных данных можно сделать вывод, что Российская Федерация находится еще только на пути к становлению законодательной базы, регулирующей отношения связанные с криптовалютой. 


\section{Библиографический список}

1. Егорова М.А., Ефимова Л.Г. Понятие и особенности правового регулирования криптовалют // Предпринимательское право. 2019. № 3. С. 11-16.

2. Пресс-релиз ЦБ РФ «Об использовании частных «виртуальных валют (криптовалют)» // URL: https://www. cbr.ru/press/pr/?file=04092017_183512if2017-09-04T18_31_05.htm (дата обращения 23.05.2021)

3. Законопроект № 419059-7 «О цифровых финансовых активах» // Система обеспечения законодательной деятельности. URL: http://sozd.parliament.gov.ru/bill/419059-7 (Дата обращения 23.05.2021)

4. Федеральный закон от 18.03.2019 № 34-Ф3 «О внесении изменений в части первую, вторую и статью 1124 части третьей Гражданского кодекса Российской Федерации Доступ из справ.-правовой системы «КонсультантПлюс» (Дата обращения 24.05.2021)

5. Белых В.С., Болобонова М. О. «Проблемы определения правового режима криптовалют» // Журнал предпринимательского и корпоративного права. 2019. № 3. С. 23.

6. Проект Федерального закона № $424632-7$ «О внесении изменений в части первую, вторую и статью 1124 части третьей Гражданского кодекса Российской Федерации» // Доступ из справ.-правовой системы «КонсультантПлюс» (дата обращения: 24.05.2021)

7. Конституция Российской Федерации (принята всенародным голосованием 12.12 .1993 с изменениями, одобренными в ходе общероссийского голосования 01.07.2020) // URL: http://www.pravo.gov.ru (дата обращения 24.05.2021)

8. Федеральный закон от 31.07.2020 № 259-Ф3 «О цифровых финансовых активах, цифровой валюте и о внесении изменений в отдельные законодательные акты Российской Федерации» // Доступ из справ-правовой системы «КонсультантПлюс» (Дата обращения: 24.05.2021)

9. Декрет Президента Республики Беларусь № 8 «О развитии цифровой экономики» г. Минск. URL: https://legal. report/uploads/doc/\%D0\%B4\%D0\%B5\%D0\%BA\%D1\%80\%D0\%B5\%D1\%828.pdf (дата обращения 15.04.2021)

10. Deutschland erkennt Bitcoins als privates Geld an // Frankfurter Allgemeine Zeitung GmbH. 2013. 16 August. (дата обращения 30.05.2021)

11. Санникова Л.В., Харитонова Ю.С. Цифровые активы: правовой анализ: монография / Л.В.Санникова, Ю. С. Хариоонова // Москва: 4 Принт, 2020.-304 с. 